\title{
A Review of Assessing Mathematical Proving Ability
}

\author{
Mohamad Waluyo $^{1}$, Tibor Vidakovich ${ }^{2}$, Naufal Ishartono ${ }^{3}$, Muhamad Toyib ${ }^{4}$ \\ \{mw192@ums.ac.id, t.vidakovich@edpsy.u-szeged.hu, ni160@ums.ac.id, \\ mt155@ums.ac.id\}
}

Universitas Muhammadiyah Surakarta, Surakarta, Indonesia ${ }^{1,3,4}$

University of Szeged, Hungary ${ }^{2}$

\begin{abstract}
Mathematical proof is a deductive argument logically composed to show the truth of a statement. The study of mathematical proofs is separated between construct a mathematical proof and comprehending a given proof. This article is aimed to discuss the notion of mathematical proving ability which is combined from two ability: construction and comprehension of proofs. The assessment of this ability is derived from assessing both construction and comprehension.
\end{abstract}

Keywords: Assessment, proofs, proving ability, mathematics, proof construction, proof comprehension

\section{Introduction}

There are many different ideas and suggestions provided by the literature on what a mathematical proof is. Proof itself is a common notion which poeple used to convince others that the statement they have made is true. At the court for instance, the attorney gives the proofs to the judge for proving that the suspect is a guilty person and deserved to be punished or contrary that the person is innocent and must be released. The proofs used can be anything including witnesses speech or documents such as photos, voice record or a videotape. Those proofs then are arranged as logic as much in order to prove and convince the judge what attorney have said is logically true. That analogy is working on mathematical proofs. Proofs in mathematics is used to investigate and show the truth of a mathematical conjecture or theorem by utilitizing mathematical statements which logically and properly composed.

Even though proofs can be used in mathematics or other applications such as law or science, yet it is still have a minor difference between them in term of the truth. Katz \& Starbird [1] claim that the truth outside mathematics was an evidence or a data for supporting a statement. for example in natural science, the truth of a claim is determined by empirical mean involving observation, measurement, and experiment. Meanwhile truth in mathematics is establish by proof that is an logically sound argument where each statement used must be logic unless the argument was denied [2]. Hence the truth outside mathematics discourse is determined by showing the existence of empirical evidence whereas the truth in mathematics is a logical value comprised in a mathematical argument. The differences on the truth decision distinguish mathematics and other empirical sciences as Healey and Hoyles said "Proof is the heart of mathematical thinking, and deductive reasoning, which ... exemplifies the distinction between mathematics and the empirical sciences" [3]. 


\subsection{Defining Mathematical Proofs}

Aforementioned explanation provides a description about proof in general but what is proof and mathematical proving itself? The scholars give several views on it. Stylianides [4] describes that mathematical proof is fundamental for knowing and doing mathematics because mathematical proof is important for understanding, communicating, and developing mathematics knowledge. Meanwhile Harel and Showder [5] said that proof in mathematics is "...the relatively precise argumentation given by mathematicians..." which is supporting what Selden and Selden [6] said "..proofs are... convincing, deductive arguments..." Moreover, Devlin [2] also exposed that "..proof in mathematics is a logically sound argument that establishes the truth of the statement..". Combining the ideas of mathematical proof mentioned can be stated that proof in mathematics is an deductive argument logically composed to show the truth of a statement.

However, every argument that has been made is not necessarily said to be a proof because the argument must be validated and accepted by others. Devlin [7] stated that the argument has been made must (i) has been accepted by a number of mathematical whom the community at large feels it can trust on such matters, and (ii) has not yet been shown to be false. This implies that aspects of recognition from others are very important to ensure that the argument is logically correct. Scholars called it as social aspect of proof. For istance, Heinze [8] said that "there is a consensus that social processes particularly play an important role in the acceptance of new scientific results, theorems, and proofs". Heinze also indicate that a tendency for mathematicians to accept a proof mainly because it was checked by themselves, produced by colleagues with high standards or published a long time ago and had not since been contradicted. Hence a proof is accepted by the mathematical community as a proof once there is social agreement that it is indeed a proof.

Other considerable aspect in an exploration of proof notion is the nature of proof. A statement or theorem is possible to be proven with a formal or informal proof. Formal proof has a formal syntax, a clear logical sequences, formulas or terms and arguments logical syntactically arranged [9]. Conversely, informal proof does not utilize certain rules such as logical sequences, logical axioms and formulas. Some mathematicians and experts argue that a textbook proof is actually formal [10] as it provides all of the information that students need to obtain a basic understanding of the proof, even though some of the logical links may not be explicitly written in the text. While informal proof is likely experienced by secondary students as using example to prove odd and even number problem [11] eventhough some undergraduate student student still using it for generalisation [12], [13]. Some philosophers even suggest this informal proof is a "real (mathematical) proof" where students produce argument by themselves [14].

Regarding the definition of mathematical proof, the researcher wants to discuss the ability of students concerned to mathematical proof and whether the ability related to proof can be assessed and how to measure it. Specifically the research questions from this literature reviewbased study are:

Research Question 1: What abilities are associated with mathematical proof?

Research Question 2: What aspects are covered in the mathematical proof ability?

Research Question 3: How do you assess this ability? 


\section{Method}

This study uses a literature review approach with a multistep processes. First, researchers conducted an online searching of peer-reviewed articles in journals or conference proceedings mainly using the google scholar search engine, ERIC and journals subscribed by the University of Szeged library. While searching, the researchers used the keywords mathematical proof, mathematical constructing arguments, assessment of mathematical proving abilities. In the searching process, the term "Mathematical Proving Ability" was not found explicitly, but several terms obtained from the literature were "proof comprehension" and "proof construction".

The second step is to combine the proof comprehension and proof construction terms into a single term to "mathematical proving abilities" and identify any evaluation tools that have been used to measure sub-components of "mathematical proving abilities". In the selection of academic literature, the researcher did not make a limitation for the year of publication so that any research relevant to the search was included in this study.

\section{Proving Ability}

Studens' ability of mathematical proof involved two aspects: ability to comprehend proof and construct proof. Those aspects altogether constitute mathematical prove ability. It is generally understood that proof construction tasks simply relate to the creation of an argument that attempts to prove a given theorem. In contrast, it is generally understood that proof comprehension relates to understanding a proof which has already been constructed.

A number of studies had been done by researchers both proof comprehension [15]-[17] and proof construction. The studies indicates that generally students experienced difficullties or made errors on both aspects. Even though most of students' difficulties found was about proof construction [18]-[20], some researchers argued that students' difficulties when facing proof comprehension or proof construction was quite similar [21]. To make it clear the differences between those aspects, this section therefore briefly confirms what is meant by proof comprehension and proof construction and the differences between the two.

\section{A. Proof comprehension}

Understanding proof is a basic element in proof ability. Understanding mathematical proof requires mathematical reasoning to determine the relationship between premises in an argument. Lin \& Yang, [15] revealed in their research about reading comprehension in geometry that the main factors influencing a person in understanding proof are logical reasoning and relevant knowledge. In general relevant knowledge helps in digesting and understanding the statements written by the author. Relevant knowledge is very helpful in understanding the evidence as in the textbook which has eliminated several steps in order to save more space. Whereas logical reasoning here plays a role in inference, namely conclusions to whether the proof is logical or not.

Furthermore, Lin \& Yang [15] and Mejia-Ramos [17] suggested four levels of proof comprehension. At the first level, termed surface, students acquire basic knowledge regarding the meaning of statements and symbols in the proof. At the second level, which Yang \& Lin [16] called recognizing the elements, students identify the logical status of the statements that are used either explicitly or implicitly in the proof. At the third level, termed chaining the elements, students comprehend the way in which these different statements are connected in the 
proof by identifying the logical relations between them. Finally, at the fourth level, referred to as encapsulation, students interiorize the proof as a whole by reflecting on how one may apply the proof to other contexts. These aspects then used to compose instrument to measure proof comprehension in their studies.

Having established the methods for measuring students' understanding of proofs, the researcher's focus is now turn on how to improve proof comprehension. This was reviewed by several researchers, including Hodd et al. [22] and Alcock et al. [23]. They conducted experiments to enhance proof comprehension using self-explanation training. They suggested that using self-explanation training increases students' cognitive engagement and the frequency with which students move their attention around a proof hence improves students' proof comprehension.

\section{B. Proof Construction}

Lee [24] define proof construction as the process of constructing mathematical assertions to determine the largest of mathematical objects for which the mathematical proposition is true or false through the search for possible examples and counterexamples. Proof construction problems are often faced by undergraduate students in subjects that are dominant in abstraction such as real analysis [25], abstract algebra [18], [26], and number theory [27], [28]. The number of difficulties were found by several researcher regarding proof construction [13], [18], [19], [29]. These difficulties are inseparable from the nature of proof constructing ability which is a very compound ability. In order to fulfill the tasks, students must have relevant knowledge, know how to generate the arguments and validate that the arguments made are logically correct to be accepted. This is supported by Boero [30], that construct a proof involves: production a conjecture includes the examination of the problem, identification the arguments which supporting the evidence and formulation of conjecture, exploration of the content of the conjecture, and identification of appropriate arguments for validation.

One important aspect in proof construction is the method of constructing the arguments. The application of appropriate method can help students in constructing a proof otherwise improper using method will instead increase the level of difficulty even causing logical errors. Some construction methods proposed by Gould \& Hurst [31] and widely utilized and studied by researchers are direct proof [32], mathematical induction [33], proof by cases [12], [34], contradiction [20] and contrapositive. In addition to these construction methods, there is also a notion of proof construction strategy. Zazkis et al. [25] proposed 2 types of strategies that is believed to have a higher success rate, called the targeted strategy and the shotgun strategy. When using a targeted strategy students would develop a strong understanding of the statement they were proving, choose a plan based on this understanding, develop a graphical argument for why the statement is true, and formalize this graphical argument into a proof. When using a shotgun strategy, students would begin trying different proof plans immediately after reading the statement and would abandon a plan at the first sign of difficulty.

Students' strategy utilitization or methods selection in proof construction is influenced by students' proof scheme. Lee [35] define a student's proof construction scheme as a cognitive scheme underlying one's proof construction [36], [37] and organization or interpretation of information concerning proof construction. According to Harel and Sowder [5] , there are three types of proof scheme.

\section{a. External conviction}

The conviction is coming from external to students where students rely on authority, the ritual, or on symbol. Authoritarian proof scheme is approved by an establish authority like 
teachers or books. While the conviction of the ritual proof scheme comes from the form of the proof such as pre-service teacher belief on two column format of geometry argument.

\section{b. Empirical proof scheme.}

Those with this proof scheme rely on evidence from examples or internal perceptions to believe a proof proves a claim. Using one or more examples to imply general truth is known as inductive proof scheme whereas perceptual proof scheme use rudimentary mental images.

\section{c. Deductive proof scheme}

With this proof scheme, a person or community believes a proof proves a claim based on logical inferences and accepted principles (axioms).

Harel and Sowder suggested that the deductive proof scheme is the ideal scheme for students to have, since it is in line with the proof scheme of mathematicians. They also suggested that students' proof schemes can be changed and refined over time.

\section{Assessment Of Mathematical Proving}

The previous discussion has disscussed two types of abilities relating to proof and proving. Research conducted by researchers mainly only supports one aspect of proof whether proof comprehension or proof construction. In this section we will try to explore the assessment method in both aspects of proving ability.

\section{Assessment Of Proof Comprehension}

Several studies have been carried out in measuring proof comprehension abilities. In the Yang \& Lin [16] study they call it reading proof comprehension because understanding proof is more dominant in the reading aspect. In their research Yang \& Lin [16] tried to compile instruments that could be used to measure the ability of reading proof comprehension for secondary school level students. They conceptualized the notion of proof comprehension from several previous studies including Duval [38], [39], Healy and Hoyles [40], Lakatos [41] and Selden \& Selden [42], [43]. Yang \& Lin [16] formulate five facets in reading proof comprehension. Those are of basic knowledge, logical status, integration or summation, generality and application or extension.

Basic knowledge status measures students' understanding of mathematical terms, images and symbols. The facet of logical status is to measure the recognition of the status of an argument, which may be premises, conclusions or applied properties of proof. Summarisation measured understanding of the given, the claims or the critical idea in a proof. The facet of generality measures the recognition of accuracy of proposition or proof and what a proof tries to prove. The facet of application is measuring the ability of knowing how to apply a proposition in the other situation. They then described the facets into 16 item numbers in the form of open question. In more detail, the Yang \& Ling [16] model is depicted in the Table 1.

Table 1. Facet of reading comprehension by Yang \& Ling [16]

\begin{tabular}{lll}
\hline Facet & \multicolumn{1}{c}{$\begin{array}{c}\text { Object of } \\
\text { comprehension }\end{array}$} & \multicolumn{1}{c}{ Operational definition } \\
\hline Basic & $\begin{array}{l}\text { Content of premise or } \\
\text { conclusion }\end{array}$ & $\begin{array}{l}\text { Recognizing the meaning of a } \\
\text { symbol } \\
\text { Recognizing and explaining the } \\
\text { meaning of a property }\end{array}$ \\
\hline $\begin{array}{l}\text { Logical } \\
\text { status }\end{array}$ & Status of premise & $\begin{array}{l}\text { recognizing a condition applied } \\
\text { directly } \\
\text { Judging the logical order of } \\
\text { statements }\end{array}$ \\
\hline premise and conclusion
\end{tabular}




\begin{tabular}{lll}
\hline Facet & \multicolumn{1}{c}{$\begin{array}{c}\text { Object of } \\
\text { comprehension }\end{array}$} & \multicolumn{1}{c}{ Operational definition } \\
& $\begin{array}{l}\text { Property applied to } \\
\text { derive conclusion from } \\
\text { premise }\end{array}$ & $\begin{array}{l}\text { Recognizing which properties } \\
\text { are applied }\end{array}$ \\
\hline Summary & $\begin{array}{l}\text { Multiple arguments and } \\
\text { critical ideas }\end{array}$ & $\begin{array}{l}\text { Identifying critical procedures, } \\
\text { premises or conclusions } \\
\text { Identifying critical ideas of a } \\
\text { proof }\end{array}$ \\
\hline Generality & $\begin{array}{l}\text { Proposition or proof } \\
\text { All arguments and } \\
\text { attached figure }\end{array}$ & $\begin{array}{l}\text { Judging the correctness } \\
\text { Identifying what is validated by } \\
\text { this proof }\end{array}$ \\
\hline Application & $\begin{array}{l}\text { Kowing to apply in other } \\
\text { situations }\end{array}$ & $\begin{array}{l}\text { Application in the same } \\
\text { premises } \\
\text { Identifying } \\
\text { premises }\end{array}$ \\
& \multicolumn{2}{c}{ different } \\
\hline
\end{tabular}

Nevertheless, the results of the analysis, according to Yang and Lin, suggested the five facets could be split into three different groups. Group one was basic knowledge, group two was logical status and summarisation and group three was generality and application. Yang and Lin conjectured that as a student acquires the skills in each group, they develop their reading comprehension of geometry proof and move through four hypothetical levels of comprehension: surface level, recognising elements, chaining elements and encapsulation. They stated that student who understand most of the terms and sentences (basic knowledge) under the context of reading a proposition and its proof is beyond the surface level and toward the secong level; another eho identifies most statements as premises, conclusions or applied properties (logical status) and catching the hardcore of this proof or the critical proof idea (summarization) is beyond the recognizing elements level and toward the third level; and one who identifies what is validated by the proof (generality) and knows how to apply the proposition or proof (application) is beyond the chaining elements level and toward the encapsulation level. The Figure 1 shows clearly model constructed by Yang \& Lin [16].

This model then replicated and modified by Mejia-Ramos et al. [17] for undergraduate proof comprehension because they argued that Yang \& Lin's model was too simplistic for modelling undergraduate proof. Furthermore, according to Mejia-Ramos et al., Yang and Lin's model did not include whether a student understands a proof in terms of higher-level ideas which mean the methods involved in the proof or how the proof relates to specific examples.

Mejia-Ramos et al developed multiple choice questions of seven different aspects of proof. The first three types of assessment address students' comprehension of only one, or a small number, of statements within the proof. They consist of the meaning of term and statement, logical status of statement and proof framework, justification and claims. The remaining four types which is called holistic address student's understanding as a whole. They are summarizing via high-level ideas, Identifying the modular structure, Transferring the general ideas or methods to another context and Illustrating with examples. The Table 2 resume the aspect of proof comprehension from Mejia-Ramos et al. [17].

Table 2. Facet of proof comprehension by Mejia-Ramos et al. [17]

\begin{tabular}{llll}
\hline Facet & Measure Student's understanding of \\
\hline Mean of terms & key terms and statements in the proof & \\
\hline Logical Status & -logical status of statements & \\
and & Proof & $\begin{array}{l}\text {-logical relationship between statements and } \\
\text { framework }\end{array}$ & statement being proven \\
\hline $\begin{array}{l}\text { Justification and } \\
\text { claims }\end{array}$ & $\begin{array}{l}\text { how each assertion in the proof follows from } \\
\text { previous statements in the proof and other proven or }\end{array}$ \\
\hline
\end{tabular}




\begin{tabular}{ll}
\hline & assumed statements. \\
\hline $\begin{array}{l}\text { Summarizing } \\
\text { high-level ideas }\end{array}$ & $\begin{array}{l}\text { students' grasp of the main idea of the proof and its } \\
\text { overarching approach. }\end{array}$ \\
\hline $\begin{array}{l}\text { Identify the } \\
\text { modular structure }\end{array}$ & $\begin{array}{l}\text { the proof in terms of its main components/modules } \\
\text { and the logical relationship between them. }\end{array}$ \\
\hline $\begin{array}{l}\text { Transferring to } \\
\text { another context }\end{array}$ & $\begin{array}{l}\text { adapt the ideas and procedures of the proof to solve } \\
\text { other proving tasks. }\end{array}$ \\
\hline $\begin{array}{l}\text { Illustrating } \\
\text { example }\end{array}$ & $\begin{array}{l}\text { The proof in terms of its relationship to specific } \\
\text { examples. }\end{array}$ \\
\hline
\end{tabular}

\section{E. Assessment Of Proof Construction}

Assessing the results of proof construction is a rather complicated thing. As well as assessing someone's essay results in the IELTS writing exam, the assessment criteria very much involve whether the writing answers the question or not, cohesion and coherence in the writing. An assessment on proof construction can be analogous to that case. The most important thing is whether the argument students composed is answering the question and whether the statement is correctly used.

Research on proof writing has been carried out by many mathematical researchers and mathematics educators. The results found are also diverse as the fact that there are still many mistakes made by students when writing a proof. These errors are various, one of them is the result of the Stavrou [19] study which makes classification of errors that are most likely done by students, namely: assuming the conclusion in order to prove the conclusion, proving general statements using specific examples, not proving both conditions in a biconditional statement and misusing definitions. Here Stavrou gets data from students' homework which he graded then he analyzes every error that occurs and categorizes it. What is not mentioned here is how he assesses the homework of the student.

Besides Stavrou, many other researchers such as Antonini and Mariotti [44], Moore [45], Selden \& Selden [42], and Weber [18] which also examined student difficulties and errors at proof construction. They pay little attention to how the proof is assessed and only respond to errors that occur. It is Moore [46] who tries to adduce the idea of the assessment of the written proof. He asked for help from 4 professors to discuss on how a good proof should be written. In general, a good proof criteria according to the professors in Moore's research are logic and clarity. Logic according to him is the most important aspect of proof because it relates to the validity of proof. Logic is referred to as the overall logical structure, or proof framework [42], the line-by-line reasoning, and the correctness of algebraic manipulations and calculations. Here proof must begin and end correctly, where the steps used are correct and logically flow from beginning to end.

The second important part of written proof assessment is clarity. Here clarity can be interpreted in various ways, namely first by mentioning explicitly the reasoning and justification of each step used, the second is proof organization so that readers can read and follow, and thirdly use language and mathematical notation correctly. Another important aspect is the issue of fluency. The purpose of fluency here is the use of language and correct mathematical notation such as grammar and punctuation. However, errors in this section are not significantly considered in proof because they have a little weight in the assessment. The last aspect is the understanding which means that students should understand what they write and a good proof shows that they understand the proof. 


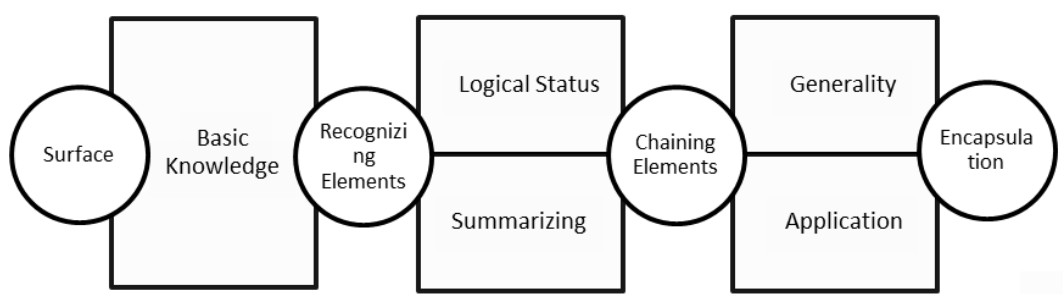

Figure 1. Four level of comprehension by Yang \& Lin (2008).

\section{F. Proof Validation}

One of the most important criteria in assessing a mathematical proof is the truth of the argument used so that the purported proof can be said to be valid. This evaluation of validity can differ between assessors from one another so that the evaluator's subjectivity cannot be avoided. Even so, Inglis et al. [47] stated in his article that most researchers from the mathematical community consider that the validity of proof is not a subjective matter. They mention "many in the mathematical community believe that the validity of a proof is not a issue of subjective but an objective fact ..." (p. 271). So that researchers with this kind of understanding of course must be able to show the consistency of their assessment of a proof.

Contrary to this assumption, Auslander [48] states that in evaluating the validity of proof it is subjective. He stated, "standards of proof vary over time and even among mathematicians at a given time" (p. 62). This can be seen from the assessment of several professors in Moore's (2016) study who gave different values for a particular argument. These two things make differences of view between mathematical scientists addressing the validity of proof.

Against this mathematician's view of proof, Weber [49] conducted an investigation and here he found that mathematicians disagreed about the validity of purported proofs. The same thing was also investigated by Inglis and Alcock [50] who concluded that disagreements among mathematicians were solely mathematical issue rather than problems of writing or presentation styles. Related to this, Inglis et al.[47] found other evidence that there was no agreement between the researchers about what was meant by valid proof in his study involving 109 participants. He added that many mathematicians who considered a proof were valid but some other mathematicians considered as invalid. Finally, it can be concluded that the standard in determining whether a proof is valid among mathematicians is different and it is possible for students to get an inconsistent understanding of a valid proof.

Beyond the differences of view on the conclusion of a proof validity, Weber [49] tried to explain how mathematician determines whether or not a proof is valid. Seven of the eight participants involved in the study made the proof validation in two phases. Weber explained that participants would first determine the structure of the argument, the proof technique being employed, that is primarily by being used in the argument. If the participants found the structure of the proof to be acceptable, he or she would then check argument each line. 


\section{Conclusion}

Study of mathematical proving ability is indirectly separated into two domains: proof construction and proof comprehension. The study of mathematical proof is dominated by study of proof construction. Later research about proof construction shows that students' performance to construct the proof still under expectation. Many of studies implies that students often make errors or misconception in making arguments on their proof. This skill is inseparable with their ability to comprehend the proof where student ability to construct is influenced by the proof they have read from text book or teacher explanation. However, the study of comprehending the proof is always separated with proof construction. That is why the authors want to investigate the ability of proving by combining the ability of comprehending and constructing the proof. The assessment of proving ability is adapted from the criteria of proof comprehension [72] and [50]. While assessing proof construction the rubric will be developed as the inexistence of aspects of proof construction.

\section{Acknowledgament}

This research was conducted in the process of doctoral education at the Doctoral School of Education, University of Szeged supported by the Stipendum Hungaricum scholarship of the Hungarian Government. While participation in the fourth international seminar of Profunedu was supported by the University of Muhammadiyah Surakarta, Indonesia, through the PID program 2018/2019.

\section{References}

[1] B. P. Katz and M. Starbird, Distilling ideas : an introduction to mathematical thinking. MAA, 2013.

[2] K. Devlin, Introduction to Mathematical Thinking. Palo Alto: Keith Devlin, 2012.

[3] N. Balacheff, "The role of the researcher' s epistemology in mathematics education : an essay on the case of proof," no. November 2002, pp. 501-512, 2008.

[4] A. J. Stylianides, "Proof and Proving in School Mathematics," J. Res. Math. Educ., vol. 38, no. 3, pp. 289-321, 2007.

[5] G. Harel and L. Sowder, "Toward Comprehensive Perspectives on the Learning and Teaching of Proof," in Second Handbook of Research on Mathematics Teaching and Learning, vol. 6179, no. 619, 2007, pp. 1-60.

[6] J. Selden and A. Selden, "Teaching Proving by Coordinating Aspects of Proofs with Students 'Abilities," in Teaching and Learning Proof Across the Grades: A K-16 Perspective, M. L. B. \& E. J. K. Despina A. Stylianou, Ed. Teaching and Learning Proof Across the Grades: A K-16 Perspective, 2009, pp. 339-354.

[7] K. Devlin, "Editorial: Proof Beyond Reasonable Doubt," Focus-The Newsletter of the Mathematical Association of America, vol. 15, no. 1, pp. 2-3, 1995.

[8] A. Heinze, "Mathematicians' individual criteria for accepting theorems and proofs: An empirical approach," in Explanation and proof in mathematics, G. Hanna, H. N. Jahnke, and H. Pulte, Eds. Springer, 2010, pp. 101-111.

[9] H. Leitgeb, "On Formal and Informal Provability," in New waves in philosophy of mathematics, London: Palgrave Macmillan, 2009, pp. 263-299.

[10] A. Aberdein, "Mathematics and Argumentation," Found Sci, vol. 14, pp. 1-8, 2009. 
[11] L. D. Edwards, "Odds and evens: Mathematical reasoning and informal proof among high school students," J. Math. Behav., vol. 17, no. 4, pp. 489-504, 1999.

[12] I. Aricha-Metzer and O. Zaslavsky, "The nature of students' productive and nonproductive example-use for proving," J. Math. Behav., vol. 53, pp. 304-322, Mar. 2019.

[13] C. K. Sari, M. Waluyo, C. M. Ainur, and E. N. Darmaningsih, "Logical errors on proving theorem," J. Phys. Conf. Ser., vol. 948, no. 1, p. 012059, Jan. 2018.

[14] M. Panza, "Mathematical Proofs," Synthese, vol. 134, no. 1, pp. 119-158, 2003.

[15] F.-L. Lin and K.-L. Yang, "The Reading Comprehension of Geometric Proofs: The Contribution of Knowledge and Reasoning," Int. J. Sci. Math. Educ., vol. 5, no. 4, pp. 729-754, Oct. 2007.

[16] K.-L. Yang and F.-L. Lin, "A model of reading comprehension of geometry proof," Educ. Stud. Math., vol. 67, no. 1, pp. 59-76, Jan. 2008.

[17] J. P. Mejia-ramos, E. Fuller, K. Weber, K. Rhoads, and A. Samkoff, "An assessment model for proof comprehension in undergraduate mathematics," pp. 3-18, 2012.

[18] K. Weber, "Student difficulty in constructing proofs: The need for strategic knowledge," Educ. Stud. Math., vol. 48, no. 1, pp. 101-119, 2001.

[19] S. G. Stavrou, "Common Errors and Misconceptions in Mathematical Proving by Education Undergraduates.," Issues Undergrad. Math. Prep. Sch. Teach., vol. 1, Mar. 2014.

[20] S. Antonini and M. A. Mariotti, "Reasoning in an absurd world: difficulties with proof by contradiction," in the 30th PME Conference, 2006, p. Vol. 2, pp. 65-72.

[21] K. Weber, "Mathematics Majors' Perceptions of Conviction, Validity, and Proof," Math. Think. Learn., vol. 12, no. 4, pp. 306-336, Oct. 2010.

[22] M. Mark Hodds, L. Lara Alcock, and M. Matthew Inglis, "Self-Explanation Training Improves Proof Comprehension," J. Res. Math. Educ., vol. 45, no. 1, pp. 62-101, 2014.

[23] L. Alcock, M. Hodds, S. Roy, and M. Inglis, "Investigating and Improving Undergraduate Proof Comprehension," Not. Am. Math. Soc., vol. 62, no. 07, pp. 742752, Aug. 2015.

[24] K. S. Lee, "Students' proof schemes for mathematical proving and disproving of propositions," J. Math. Behav., vol. 41, pp. 26-44, 2016.

[25] D. Zazkis, K. Weber, and J. P. Mejía-Ramos, "Two proving strategies of highly successful mathematics majors," J. Math. Behav., vol. 39, pp. 11-27, 2015.

[26] T. P. Fukawa-Connelly, "A case study of one instructor's lecture-based teaching of proof in abstract algebra: making sense of her pedagogical moves," Educ. Stud. Math., vol. 81, no. 3, pp. 325-345, Nov. 2012.

[27] K. Lew and D. Zazkis, 'Undergraduate mathematics students' at-home exploration of a prove-or-disprove task," J. Math. Behav., vol. 54, p. 100674, Jun. 2019.

[28] M. Inglis, J. P. Mejia-Ramos, and A. Simpson, "Modelling mathematical argumentation: the importance of qualification," Educ. Stud. Math., vol. 66, no. 1, pp. 3-21, Aug. 2007.

[29] M. Waluyo and C. K. Sari, "Kesalahan Penalaran Dalam Pembuktian Masalah Struktur Aljabar,” JIPMat, vol. 2, no. 2, pp. 116-121, Dec. 2017.

[30] P. Boero, "Argumentation and mathematical proof: A complex, productive, unavoidable relationship in mathematics and mathematics education," International newsletter on the teaching and learning of mathematical proof, p. 7(8), 1999.

[31] M. Gould and E. Hurst, "Proof Methods," in Bridging the Gap to University 
Mathematics, London: Springer Netherlands, 2009, pp. 1-11.

[32] U. Leron, "A direct approach to indirect proofs," Educ. Stud. Math., vol. 16, no. 3, pp. 321-325, Aug. 1985.

[33] G. J. Stylianides, J. Sandefur, and A. Watson, "Conditions for proving by mathematical induction to be explanatory," J. Math. Behav., vol. 43, pp. 20-34, Sep. 2016.

[34] E. Knuth, O. Zaslavsky, and A. Ellis, "The role and use of examples in learning to prove," J. Math. Behav., vol. 53, pp. 256-262, Mar. 2019.

[35] K. Lee, "Students' proof schemes for mathematical proving and disproving of propositions," J. Math. Behav., vol. 41, pp. 26-44, Mar. 2016.

[36] N. Balacheff, "Aspects of proof in pupils' practice of school mathematics," in Mathematics, teachers and children, E. Pimm, Ed. Londres: Hodder \& Stoughton, 1988, pp. 216-235.

[37] G. Harel and L. Sowder, "Students' Proof Schemes: results from exploratory studies," in Research on Collegiate Mathematics Education, A. Schoenfeld, J. Kaput, and E. Dubinsky, Eds. M.M.A. and A.M.S., 1998, pp. 234-283.

[38] R. Duval, "Geometry from a cognitive point of view," in Perspectives on the teaching of geometry for the 21st century. An International Commission on Mathematical Instruction (ICMI) Study [Chapter 2.2]., 1998.

[39] R. Duval, "Proof understanding in mathematics: What ways for students?," in Proceedings of the international conference on mathematics: Understanding proving and proving to understand, 2002, pp. 61-77.

[40] L. Healy and C. Hoyles, "A Study of Proof Conceptions in Algebra," J. Res. Math. Educ., vol. 31, no. 4, p. 396, Jul. 2000.

[41] I. Lakatos, Proofs and refutations : the logic of mathematical discovery. Cambridge University Press, 1976.

[42] J. Selden and A. Selden, "Unpacking the logic of mathematical statements," Educ. Stud. Math., vol. 29, no. 2, pp. 123-151, Sep. 1995.

[43] A. Selden and J. Selden, "Validations of Proofs Considered as Texts: Can Undergraduates Tell Whether an Argument Proves a Theorem?," J. Res. Math. Educ., vol. 34, no. 1, p. 4, Jan. 2003.

[44] S. Antonini and M. A. Mariotti, "Indirect proof: what is specific to this way of proving?," ZDM, vol. 40, no. 3, pp. 401-412, Aug. 2008.

[45] R. C. Moore, "Making the transition to formal proof," Educ. Stud. Math., vol. 27, no. 3, pp. 249-266, Oct. 1994.

[46] R. C. Moore, "Mathematics Professors ' Evaluation of Students ' Proofs : A Complex Teaching Practice," Int. J. Res. Undergrad. Math. Educ., pp. 246-278, 2016.

[47] M. Inglis, J. P. Mejia-Ramos, K. Weber, and L. Alcock, "On Mathematicians' Different Standards When Evaluating Elementary Proofs," Top. Cogn. Sci., vol. 5, no. 2, pp. 270-282, Apr. 2013.

[48] J. Auslander, "On the roles of proof in mathematics," in Proof and Other Dilemmas: Mathematics and Philosophy, Bonnie Gold and Roger Simons, Eds. Mathematical Association of America, 2008, pp. 61-77.

[49] K. Weber, "How Mathematicians Determine if an Argument Is a Valid Proof," J. Res. Math. Educ., vol. 39, no. 4, pp. 431-459, 2008.

[50] M. Inglis and L. Alcock, "Expert and Novice Approaches to Reading Mathematical Proofs," J. Res. Math. Educ., vol. 43, no. 4, pp. 358-390, 2012. 